\title{
The effect of RMI 12,936, a synthetic antiprogestational steroid, on ovarian steroidogenesis in the rat
}

\author{
D. G. Hardy, K. E. Kendle, M. R. Lawrie and H. E. Omand \\ School of Pharmacy, Robert Gordon's Institute, Schoolhill, Aberdeen, AB9 IFR, U.K.
}

\begin{abstract}
Summary. A series of physiochemical investigations confirmed that the product of chemical and enzymatic isomerization of RMI 12,936 was $7 \alpha$-methyltestosterone. The total activity per pair of ovaries of $\Delta^{5} 3$-ketosteroid isomerase in vitro was unchanged by RMI 12,936 pretreatment or by advancing pregnancy, significant changes in ovarian weight being accompanied by reciprocal changes in enzyme activity/mg tissue. The initial linear rate of isomerization of RMI 12,936 was approximately five times greater than the corresponding rate of $\Delta^{5}$-progesterone isomerization at equal substrate concentrations. It is concluded that RMI 12,936 does not inhibit progesterone biosynthesis by alteration of $\Delta^{5} 3$-ketosteroid isomerase activity, but that it may do so by acting as an alternative substrate for this enzyme.
\end{abstract}

\section{Introduction}

The substance RMI 12,936 (17 $\beta$-hydroxy-7 $\alpha$-methylandrost-5-en-3-one) was claimed by its discoverers (U.S. Patent $3,833,621$ issued 3 September 1974) to possess marked antiprogestational activity. Preliminary studies in the rat (Kendle, 1975) confirmed that RMI 12,936 had a similar potency to ethinyloestradiol in antifertility tests but was only $1 / 10,000$ th as potent as ethinyloestradiol in the rat vaginal cornification test. From these data it was concluded that RMI 12,936 did possess marked antifertility activity which was not due to oestrogenic activity and was probably an indication of specific antiprogestational effect, probably on progesterone utilization rather than on progesterone production.

From further work (Kendle, 1976) it was concluded that RMI 12,936 inhibits the biosynthesis of progesterone and is metabolized to a substance believed to be $7 \alpha$-methyltestosterone (Isomer 201), the metabolite probably being a competitive antagonist of progesterone at the receptor level. The observation that ovarian hypertrophy on Day 15 was associated with normal progesterone secretion led to the hypothesis that treatment with RMI 12,936 might cause enzyme induction resulting in elevated levels of $\Delta^{5} 3$-ketosteroid isomerase, while the reduction in progesterone secretion on Day 9 may be due to inhibition of this enzyme. The aims of the present study, therefore, were to confirm that RMI 12,936 is metabolized to $7 \alpha$-methyltestosterone and to investigate whether administration of RMI 12,936 results in changes in $\Delta^{5} 3$-ketosteroid isomerase activity and whether RMI 12,936 may be acting as an alternative substrate for this enzyme.

\section{Methods and Results}

\section{Confirmation of the chemical structure of Isomer 201}

Isomer 201 was prepared by the chemical isomerization of RMI 12,936 as described previously (Kendle, 1976) and compared with a pure sample of $7 \alpha$-methyltestosterone. Both samples had m.p. and mixed m.p. (uncorrected) of $214-215^{\circ} \mathrm{C}$ : previous values are $211-214^{\circ} \mathrm{C}$ (Campbell \& Babcock, 1959 ) and $214-218^{\circ} \mathrm{C}$ (Wieland \& Anner, 1967).

Thin-layer chromatography. Spots of $2 \mu$ of a $1 \%$ solution in ethanol of Isomer 201, 7 $\alpha$-methyltestosterone and a mixture of the two were run on silica gel plates with a solvent of $n$-hexane :ether : 
glacial acetic acid ( $40: 60: 2$ by vol.). Plates were examined under u.v. light, sprayed with LiebermanBurchard reagent and re-examined in daylight and u.v. light. For each sample a single spot was obtained which had an $R_{F}$ value of $0 \cdot 17$ and each gave the same green coloration with the LiebermanBurchard reagent. Similar results were obtained when the experiment was repeated using chloroform and ethyl acetate : chloroform $(10: 90 \mathrm{v} / \mathrm{v})$ as solvents.

In a similar experiment with the n-hexane :ether : glacial acetic acid solvent, Isomer 201, 7amethyltestosterone and a mixture of the two again gave single spots $\left(R_{F}=0 \cdot 17\right)$, while RMI 12,936 gave a spot (green with the Lieberman-Burchard reagent) of $\boldsymbol{R}_{\boldsymbol{F}}$ value $0 \cdot 29$. After incubation with rat ovarian homogenate, however, RMI 12,936 gave two spots, one of which corresponded to unchanged material and the other to $7 \alpha$-methyltestosterone.

Cross-reaction in the competitive protein-binding assay for progesterone. Samples of Isomer 201 and $7 \alpha$-methyltestosterone were examined for cross-reaction in this assay at the Department of Obstetrics and Gynaecology, Aberdeen Royal Infirmary, using the method described previously (Kendle, 1976). At the time of examination the investigator was unaware of the probable relationship between these substances. The results showed that $6.29 \mathrm{ng}$ progesterone were equivalent to $79.2 \mathrm{ng}$ Isomer 201 and $82.0 \mathrm{ng} 7 \alpha$-methyltestosterone. Therefore the cross-reactions of Isomer 201 and $7 \alpha$-methyltestosterone were $7.9 \%$ and $7.7 \%$ of the progesterone standard respectively. Previous investigations (Kendle, 1976) showed the cross-reaction of Isomer 201 in this assay to be $7.8 \%$.

Infrared, u.v. and nuclear magnetic resonance spectroscopy. Isomer 201 and $7 a$-methyltestosterone had identical spectra, the main features of which were as follows: infrared (in dichloromethane)bands at $3600 \mathrm{~cm}^{-1}$ (hydroxyl), $1665 \mathrm{~cm}^{-1}$ and $1615 \mathrm{~cm}^{-1}$ ( $\alpha \beta$-unsaturated 6-membered ring ketone); ultraviolet (in $95 \%$ ethanol) $-\lambda_{\max } 242 \mathrm{~nm}, \varepsilon 16,760$ (Campbell \& Babcock (1959) give $\lambda_{\max } 242 \mathrm{~nm}$, $\varepsilon 16,050)$; nuclear magnetic resonance $(100 \mathrm{MHz})$ - sharp peaks at 0.80 and $1.20 \mathrm{ppm}(\mathrm{C}-18$ and C-19 protons respectively), broad triplet at 3.7 p.p.m. (C-17 proton), sharp doublet at 5.72 p.p.m., J (coupling constant) $=1.8 \mathrm{~Hz}(\mathrm{C}-4$ proton in allylic coupling with axial $6 \beta$-proton); (features described by Wittstruck, Malhotra \& Ringold, 1963).

\section{Ovarian $\Delta^{5}$ steroid isomerase activity}

Female rats of the Sprague-Dawley strain were maintained as described previously (Kendle, 1975). The day on which spermatozoa were found in the vaginal lavage was designated Day 1 of pregnancy. RMI 12,936 was administered subcutaneously suspended in an aqueous vehicle containing $0.25 \%(\mathrm{w} / \mathrm{v})$ sodium carboxymethyl cellulose and $1 \%(\mathrm{w} / \mathrm{v})$ Tween 80 , the dose volume being $0.5 \mathrm{ml}$. The animals were killed at the required stage of pregnancy by cervical dislocation and the ovaries were removed. Each pair of ovaries was weighed to the nearest $0.1 \mathrm{mg}$ and homogenized in 50 or 100 volumes of Krebs-Ringer phosphate buffer, pH 7•4, using a glass homogenizer with a mechanically driven Teflon pestle (Thomas tissue grinder: Arthur $\mathrm{H}$. Thomas Co., Philadelphia) for 2 min at $0^{\circ} \mathrm{C}$. The homogenates were centrifuged at $800 \mathrm{~g}$ for $10 \mathrm{~min}$ at $0^{\circ} \mathrm{C}$ to remove cellular debris and suitable aliquots of the supernatant were taken for incubation. All glassware was cleaned by overnight soaking in a solution of a non-adsorbent surface-active agent (Decon: Decon Laboratories Ltd, Brighton) followed by thorough rinsing and drying in an oven.

The enzyme activity, using RMI 12,936 as a substrate, was calculated as the initial linear rate of reaction expressed as nmol substrate converted $/ \mathrm{min} / \mathrm{mg}$ wet weight of tissue. The steroid was dissolved in ethanol immediately before use to prevent spontaneous isomerization. Addition of $0.5 \mathrm{ml}$ of this solution to $2 \mathrm{ml}$ aliquots of homogenate gave a final steroid concentration of $0.001 \mathrm{M}$. This concentration was sufficient for maintenance of the initial linear rate of reaction for more than 5 min (preliminary study) and incubation periods of $5 \mathrm{~min}$ were therefore used. Incubations of ovarian homogenates in buffer at $37^{\circ} \mathrm{C}$ without substrate and steroid were the controls. The incubations were terminated by immersing the tube in ice and adding $2 \mathrm{ml}$ hexane, previously cooled to $0^{\circ} \mathrm{C}$. Preliminary experiments showed that the relationship between u.v. absorbance at $243 \mathrm{~nm}$ and concentration of $7 \alpha$-methyltestosterone in hexane was linear over the concentration range of $1-8 \times 10^{-5} \mathrm{M}$, and that complete extraction of $7 \alpha$-methyltestosterone from ovarian homogenate could be achieved by shaking twice with $2 \mathrm{ml}$ hexane. 
Rats were given a s.c. injection of $2 \mathrm{mg} \mathrm{RMI} 12,936$ or the vehicle only on Day 8 of pregnancy. Five animals from each group were killed on Day 9 and a further 9 from each group were killed on Day 15.

All the control animals were still pregnant at autopsy, but total fetal resorption was present in the treated rats killed on Day 15. Implantation and decidualization in the treated animals killed on Day 9 were similar to those of the control rats at this stage of pregnancy. Although the treatment with RMI 12,936 was effective in terminating pregnancy by Day 15, the results in Table 1 show that it did not, in this experiment, cause significant ovarian hypertrophy, and there were no significant differences between the $\Delta^{5}$ steroid isomerase activities in treated and control animals $(P>0.05)$. The significant $(P<0.01)$ increase in ovarian weight between Days 9 and 15 in the treated and control rats was accompanied by a significant $(P<0.01)$ decrease in isomerase activity per mg tissue (Student's $t$ test).

Table 1. Effect of RMI 12,936 (mean \pm S.E.M.) on $\Delta^{5}$ 3-ketosteroid isomerase activity in the ovary of the pregnant rat

\begin{tabular}{cccccc}
\hline $\begin{array}{c}\text { Dose of } \\
\text { RMI 12,936 (mg) }\end{array}$ & $\begin{array}{c}\text { Day of } \\
\text { autopsy }\end{array}$ & $\begin{array}{c}\text { No. of } \\
\text { replicates }\end{array}$ & Ovarian wt (mg) & \multicolumn{3}{c}{$\begin{array}{c}\text { Enzyme activity } \\
\text { (nmol substrate converted/min) }\end{array}$} \\
\hline 0 & 9 & 5 & $58.3 \pm 5.5$ & $0.774 \pm 0.090$ & $45.28 \pm 6.88$ \\
2 & 9 & 5 & $58.94 \pm 1.0$ & $0.772 \pm 0.113$ & $45.88 \pm 7.44$ \\
0 & 15 & 9 & $112.2 \pm 3.3$ & $0.328 \pm 0.039$ & $36.32 \pm 4.21$ \\
2 & 15 & 9 & $117.8 \pm 5.0$ & $0.407 \pm 0.037$ & $47.89 \pm 5.09$ \\
\hline
\end{tabular}

\section{Reaction time course}

This was determined using RMI 12,936 and $\Delta^{5}$ progesterone as substrates for incubations of homogenates of the ovaries of untreated pregnant rats killed on Day 15 . The $\Delta^{5}$ progesterone substrate was prepared from pregnenolone by the chromium trioxide oxidation method described by Djerassi, Engles \& Bowers (1956) and its identity and purity checked by i.r., u.v. and n.m.r. spectra, and thin-layer chromatography on silica gel plates using n-hexane : ether : glacial acetic acid (40:60: by vol.) as the solvent.

All the incubation conditions were as in the previous experiment except that incubation times of $1 \cdot 25,2 \cdot 5,5,10,20$ and 40 min were used. The results given in Text-fig. 1 show that at equivalent substrate concentrations the rate of isomerization of RMI 12,936 is higher than that of $\Delta^{5}$ progesterone.

\section{Discussion}

All the tests used confirm that Isomer 201 is identical with the expected product, $7 \alpha$-methyltestosterone. There was no change in total ovarian $\Delta^{5}$ steroid isomerase activity either as a result of advancing pregnancy or treatment with RMI 12,936, suggesting that this enzyme is maintained at a steady concentration, unlike ovarian $3 \beta$-hydroxysteroid dehydrogenase which has been shown to undergo a threefold increase in activity between Days 9 and 15 of pregnancy in the rat (Marcal, Chew, Soloman \& Sherma, 1975). It may therefore be concluded that the rate of $\Delta^{5} 3$-ketosteroid isomerization is controlled by substrate availability rather than by variation in enzyme activity.

Previous studies (Kendle, 1975, 1976) have shown that doses of 2 mg RMI 12,936 rat were high enough to terminate pregnancy in all animals and resulted in ovarian hypertrophy. Hypertrophy was not induced in the present experiments and has previously been absent after low doses of RMI 12,936 which have a reduced antifertility effect. It may be concluded, therefore, that the dose of RMI 12,936 which causes ovarian hypertrophy is probably higher than the dose required to prevent pregnancy. 


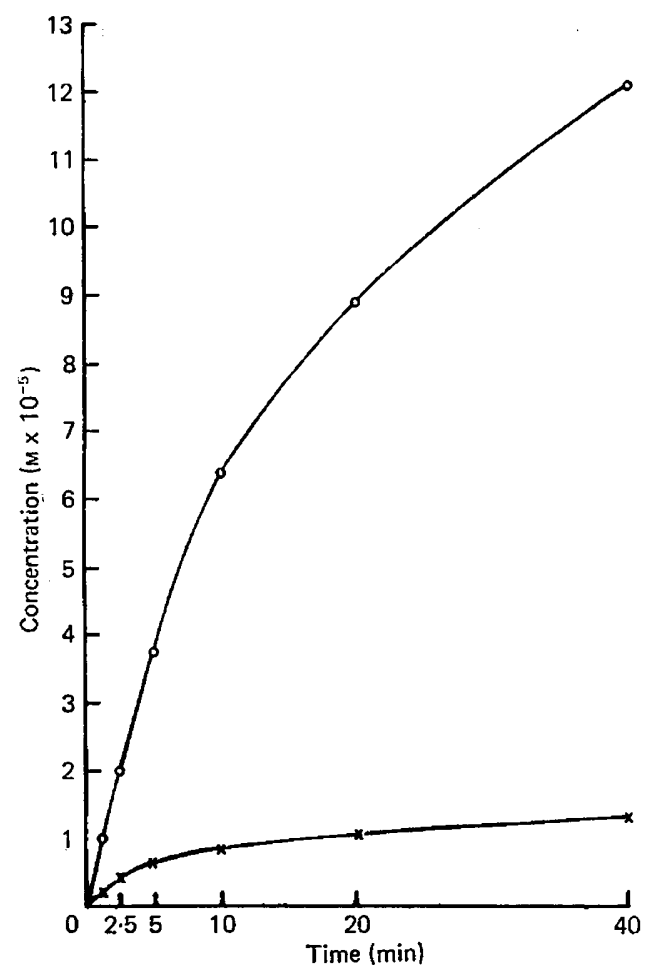

Text-fig.1. The rates of production of $7 \alpha$-methyltestosterone from RMI 12,936 (0) and of progesterone from $\Delta^{5}$ progesterone $(x)$ by homogenates of rat ovaries at equivalent initial substrate concentrations $\left(10^{-3} \mathrm{M}\right)$. Each point was obtained from duplicate samples withdrawn from pooled homogenates of ovaries from 5 rats.

The significant increase in ovarian weight occurring during pregnancy was not accompanied by significant change in the total activity of the $\Delta^{5}$ steroid isomerase. It would seem unlikely, therefore, that the ovarian enlargement previously produced by RMI 12,936 was due to increases in the activity of this enzyme and would rule out isomerase induction as a mechanism of ovarian hypertrophy unless it could be shown that the enzyme was inactivated by RMI 12,936. Further investigation of the mechanism of ovarian hypertrophy is required, but the present results show that this phenomenon is not an essential part of the antifertility activity of RMI 12,936.

The results of the experiment to determine whether RMI 12,936 might act as a preferred substrate for $\Delta^{5}$ 3-ketosteroid isomerase and therefore be converted to $7 \alpha$-methyltestosterone in preference to the conversion of $\Delta^{5}$ progesterone to progesterone show that the initial linear rate of conversion of RMI 12,936 to 7a-methyltestosterone was higher, by a factor of approximately five. Further studies are necessary, however, to determine whether the rates are altered by the addition of the two substrates simultaneously and also to determine the effect of changes in substrate concentration using analytical methods which will allow separation and measurement of the two expected products. The evidence to date suggests that RMI 12,936 is more likely to interfere with progesterone biosynthesis by acting as a preferred substrate for $\Delta^{5} 3$-ketosteroid isomerase than by alterations in the activity of this enzyme.

We thank Dr V. Petrow and Merrell National Laboratories Division of Richardson Merrell Inc., Cincinnati, Ohio, for supplying RMI 12,936 and 7 $\alpha$-methyltestosterone; Professor A. Klopper and Mr D. Bruce, Department of Obstetrics and Gynaecology, Aberdeen Royal Infirmary, for provision of laboratory facilities and for help; and Mr A. Wilson, School of Mathematics, Robert Gordon's Institute of Technology, Aberdeen, for the statistical analysis of results. 


\section{References}

CAMPBell, J.A. \& BabCoCK. J.C. (1959) The synthesis of some $7 \alpha$ - and $7 \beta$-methyl steroid hormones. J. Am. chem. Soc. 81, 4969-4074.

Djerassi, C., Engles, R.R. \& Bowers, A. (1956) The direct conversion of steroidal $\Delta^{5} 3 \beta$-alcohols to $\Delta^{4}$ 3-ketones.J. org. Chem. 21, 1547-1549.

KENDLE, K.E. (1975) Some biological properties of RMI 12,936 , a new synthetic antiprogestational steroid. J. Reprod. Fert. 43, 505-513.

KENDLE, K.E. (1976) Effects of RMI 12,936, a synthetic antiprogestational steroid, in the rat. $J$. Reprod. Fert.
48, 159-166.

Marcal, J.M., Chew, N.J., SOlomon, D.S. \& ShERMa, N.I. (1975) $\Delta^{5} 3 \beta$-Hydroxysteroid dehydrogenase activity in rat trophoblast and ovary during pregnancy. Endocrinology 96, 1270-1279.

WIELAND, P. \& ANNER, G. (1967) Synthese von 7 $\alpha$ Methylöstron. Helv. chim. Acta 50, 289-296.

WitTstruCK, T.A., MALHOTRA, S.K. \& RINGOLD, H.J. (1963) Concerning the steric requirements for the allylic 1,3 -spin-spin coupling of protons. J. Am. chem. Soc. 85, 1699-1700.

Received 29 Jume 1976 